\title{
A Paradoxical Effect?
}

Ann Fam Med 2014;12(4):iii. doi:10.1370/afm.1681.

$\mathrm{T}$ The Annals of Family Medicine encourages readers to develop a learning community of those seeking to improve health care and health through enhanced primary care. You can participate by conducting a RADICAL journal club and sharing the results of your discussions in the Annals online discussion for the featured articles. RADICAL is an acronym for Read, Ask, Discuss, Inquire, Collaborate, Act, and Learn. The word radical also indicates the need to engage diverse participants in thinking critically about important issues affecting primary care and then acting on those discussions. ${ }^{1}$

\section{HOW IT WORKS}

In each issue, the Annals selects an article or articles and provides discussion tips and questions. We encourage you to take a RADICAL approach to these materials and to post a summary of your conversation in our online discussion. (Open the article online and click on "TRACK Comments: Submit a comment.") You can find discussion questions and more information online at: http://www.AnnFamMed.org/site/AJC/.

\section{CURRENT SELECTION}

Liss DT, Reid RJ, Grembowski D, Rutter CM, Ross TR, Fishman PA. Changes in office visit use associated with electronic messaging and telephone encounters among patients with diabetes in the PCMH. Ann Fam Med. 2014;12(4):338-343.

\section{Discussion Tips}

This article provides an opportunity to consider findings from one novel component of a patient-centered medical home intervention. The study provides an example of the increasingly commonly used interrupted time series design for studying natural experiments, and requires consideration of contextual factors in interpreting and transporting the findings.

\section{Discussion Questions}

- What question is asked by this study and why does it matter?
- How does this study advance beyond previous research and clinical practice on this topic?

- How strong is the study design for answering the question? What alternatives exist for learning from this kind of real world experiment?

- To what degree can the findings be accounted for by: 1. How patients were selected, excluded, or lost to follow-up?

2. How the main variables were measured?

3. Confounding (false attribution of causality because 2 variables discovered to be associated actually are associated with a 3 rd factor)?

4. Chance?

5. How the findings were interpreted?

- How were potential threats to validity dealt with in the study design and analysis approach?

- What are the main study findings?

- How do you interpret the differences between the crude and regression analyses? How do you interpret the attenuation over time of the association between office visits and telephone encounters?

- How comparable is the study sample to similar patients in your practice? What is your judgment about the transportability of the findings?

- What contextual factors are important for interpreting the findings (ie the nesting of this study within an ongoing patient-centered medical home initiative within an integrated health care system)?

- How might this study change your practice? Policy? Education? Research?

- Who are the constituencies for the findings, and how might they be engaged in interpreting or using the findings?

- What are the next steps in interpreting or applying the findings?

-What researchable questions remain?

\section{References}

1. Stange KC, Miller WL, McLellan LA, et al. Annals Journal Club: It's time to get RADICAL. Ann Fam Med. 2006;4(3):196-197. http:// annfammed.org/cgi/content/full/4/3/196. 